* Émilien Vilas Boas Reis: Graduado em Filosofia (UFMG), mestre e doutor em Filosofia (PUCRS). Pós-doutor em filosofia (FLUP-Porto). Professor de Filosofia e Filosofia do Direito do programa de graduação e pós-graduação (mestrado) em Direito da Escola Superior Dom Helder Câmara (BH). mboasr@ yahoo.com.br

** Marina Lage Pessoa Costa: Defensora Pública do Estado de Minas Gerais. Conselheira do Conselho de Criminologia e Política Criminal do Estado de Minas Gerais. Especialista em Direito Civil pelo IEC- PUCMINAS - Instituto de Educação Continuada da Pontifícia Universidade Católica de Minas Gerais. Mestranda em Direito Ambiental e Desenvolvimento Sustentável pela ESDHC - Escola Superior Dom Helder Câmara (Belo Horizonte). marinalage@ gmail.com

\section{A concretização do ordenamento jurídico ambiental sob a luz do pensamento habermasiano}

\author{
THE IMPLEMENTATION OF ENVIRONMENTAL \\ PROTECTION NORMS UNDER THE THOUGHT OF \\ HABERMASIAN THEORY
}

\author{
Émilien Vilas Boas Reis* \\ Marina Lage Pessoa Costa**
}

Resumo: O presente estudo tem por objeto a análise das normas de proteção ambiental a partir da Conferência de Estocolmo Sobre Meio Ambiente Humano sob a luz do pensamento habermasiano, avaliando legitimidade das normas e sua efetividade a partir da perspectiva do sujeito de deveres ambientais. Demonstra-se que a discussão das normas e política ambientais pela via da ação comunicativa proposta por Habermas viabiliza tanto a legitimidade das normas e sua efetividade pelo cidadão, como a construção do consenso inarredável à construção das normas e política ambientais no âmbito internacional, tendo em vista a abertura do espaço para a apresentação de críticas e a observância de uma linguagem que viabiliza o entendimento sobre o conteúdo das proposições.

Palavras-Chave: Convenção de Estocolmo. Eficácia das normas ambientais. Habermas.

Abstract: The present study aims at the analysis of the environmental protection regulations from the Stockholm Conference on Human Environment under thought of Habermasian theory, evaluating standards of legitimacy and its effectiveness from a citizen as a subject of environmental obligations. Demonstrates that the discussion of standards and environmental policy through communicative action by Habermas proposal, enables both the legitimacy of standards and its effectiveness by the citizen, as the construction of consensus standards and environmental policy in the international arena, with a view to opening up the space for the presentation of criticism and the observance of a language that enables the understanding of the content of propositions.

Keywords: Stockholm convention human rights. Effectiveness of environmental regulations. Habermas. 


\section{INTRODUÇÃO}

O mundo vive uma grave crise ambiental, fruto de um modelo de crescimento econômico e demográfico implantado no curso do século XX, apresentando sérios problemas como extinção de espécimes da fauna e flora acarretando redução da biodiversidade, esgotamento de recursos naturais, a escassez de água, aquecimento global, poluições em níveis alarmantes, afetando diretamente a qualidade de vida dos seres humanos.

A partir da década de 60 inicia-se um movimento de conscientização sobre a relevância da proteção ao meio ambiente. Vários fatores como as tragédias ambientais e as novas descobertas científicas sobre as ameaças aos recursos naturais contribuíram para uma mobilização popular em defesa do meio ambiente.

O crescimento econômico e a industrialização predatória trouxeram resultados preocupantes para o mundo como a poluição do ar, da água e do solo. Nesse contexto, a Suécia propôs à ONU a realização de uma conferência internacional na qual fosse possível discutir os problemas ambientais de dimensões globais e as questões socioeconômicas, principalmente no que se referia ao crescimento demográfico sobre os recursos naturais nos países pobres.

No mesmo período, no âmbito mundial, algumas organizações ambientais não governamentais despontavam de forma expressiva em defesa do planeta, por meio de denúncias e alertas. Além disso, diversos setores da sociedade estavam descontentes quanto às repercussões da poluição sobre a qualidade de vida de seus cidadãos.

Esses movimentos associados à crescente atenção internacional para a preservação da natureza pressionaram politicamente os Poderes Públicos dos países a se manifestarem. Nesse cenário de intensos debates ambientais, os governantes de cento e treze países se reuniram para discutir, em Estocolmo, as principais questões ambientais vigentes à época.

Nesse sentido, a Conferência de Estocolmo Sobre Meio Ambiente Humano se tornou uma das mais importantes tentativas de se estabelecer parâmetros de orientação de normas internacionais de proteção ambiental. Com ela, iniciou-se um debate global sobre meio ambiente e suas implicações dentro de um contexto internacional. Houve a inserção e o envolvimento dos Estados nas questões relativas ao ambiente, no intuito de nivelar em um mesmo discurso desenvolvimento, crescimento econômico e defesa ambiental. 
A Concretização do ordenamento jurídico ambiental sob a luz do pensamento habermasiano

A Declaração de Estocolmo foi o alicerce para a construção do artigo 225 da Constituição da República de 1988 (BRASIL), segundo o qual "todos têm o direito ao meio ambiente ecologicamente equilibrado, bem de uso comum do povo e essencial à sadia qualidade de vida, impondo-se ao Poder Público e à coletividade o dever de defendê-lo e preservá-lo para as presentes e futuras gerações."

O presente artigo tem por objeto a análise da influência da Declaração de Estocolmo e do contexto internacional na Constituição da República do Brasil de 1988 quanto à previsão normativa referente à proteção ambiental. Para tanto, aborda-se a correlação entre Meio Ambiente, Direito Fundamental e Direitos Humanos, desenvolvendo a ideia de que o desafio do Direito Ambiental é sua efetividade.

Tem-se por marco teórico o pensamento jurídico filosófico de Habermas para auxiliar neste desiderato.

A metodologia utilizada na consecução deste artigo consiste basicamente no método analítico-descritivo. Utilizou-se também como fonte de pesquisa informações eletrônicas em sítios especializados e artigos científicos.

\section{A CONVENÇÃO DE ESTOCOLMO (1972)}

A Conferência de Estocolmo foi a primeira grande reunião organizada pelas Nações Unidas a concentrar-se sobre questões de meio ambiente. Ela anunciou alguns dos conceitos e princípios que, ao longo dos anos, se tornariam a base sobre a qual evoluiria toda a diplomacia ambiental. Por isso, o ano de 1972 se tornou um marco para a história da proteção ambiental mundial.

Segundo Karin Kässmayer (2010, p.227):

Sem dúvida, a sociedade, de um modo geral, preocupa-se com o tema meio ambiente, bem como estudiosos das mais diversas áreas do conhecimento humano. O pensar ecológico (grifo do autor) não se restringe mais ao âmbito técnico-científico, mas ultrapassa ao campo político, econômico e social. No Direito, refletiu-se igualmente a defesa ao ambiente saudável, frente aos fatos ocorridos nas últimas décadas (aceleração tecnológica, pressão demográfica, urbanização, aumento da exploração dos recursos naturais, expansão do domínio da energia nuclear, etc.) e ao anseio da sociedade em proteger o meio ambiente, pois este garante, em parte, a concretização dos direitos fundamentais à vida e à dignidade humana. 
Diante da premente necessidade de se estabelecer uma atitude concreta entre os países, para evitar a destruição ambiental, foram reconhecidos alguns princípios na Convenção de Estocolmo considerados desdobramentos da Declaração Universal dos Direitos do Homem. Segundo afirma Romeu Thomé (2012, p.43):

A Declaração destaca o ser humano como resultado e artífice do meio que o circunda, proclama que a defesa e a melhoria do meio ambiente para as gerações presentes e futuras converte-se num objetivo imperioso para a humanidade e deverá ser perseguido e, ainda, sugere que cidadãos e comunidade, empresas e instituições em todos os planos aceitem as responsabilidades que lhes incumbem e que todos eles atuem efetivamente para a preservação ambiental. Surgia a noção de desenvolvimento socioeconômico em harmonia com a preservação do meio ambiente, mais tarde batizada de "desenvolvimento sustentável." (grifo do autor).

Pretendeu-se criar, então, uma sistemática universal de controle entre os Estados. Da mesma forma, a Conferência de Estocolmo tentou reunir e disciplinar a temática ambiental sob o prisma de proteção ambiental universal a ser adotada por todos os países. Nasce aqui a tentativa de cooperação entre os Estados em prol do meio ambiente.

Segundo ressalta Édis Milaré (2011, p.1511), "a Declaração de Estocolmo traz em seu bojo a cooperação internacional para a proteção do meio ambiente como princípio geral de Direito Internacional embora com ênfase no livre intercâmbio de experiências científicas e na tecnologia ambiental".

Para tanto, a Declaração de Estocolmo estabeleceu vinte e seis princípios que ressaltam a importância do direito à dignidade e ao bem-estar. Também alicerçou vários outros expressivos encontros internacionais e possibilitou que a postura ambiental fosse adotada constitucionalmente nos países, como um Direito Fundamental entre os direitos sociais do homem. Ela reconheceu o meio ambiente como Direito Fundamental do ser humano. (KÄSSMAYER, 2010).

Com isso, vários seminários sobre estilos alternativos de desenvolvimento foram realizados. Como consequência direta da Conferência de Estocolmo, foi institucionalizado o Programa das Nações Unidas para o meio ambiente PNUMA - que objetivou promover a conservação do meio ambiente e o uso eficiente dos recursos naturais e a aprovação da Declaração sobre o Meio Ambiente Humano. 
Além desses, também como resultado dos debates, originou-se o Relatório Brundtland em 1987, dentre outros.

Portanto, pode-se verificar que o meio ambiente necessita de uma proteção maior, segundo as palavras do autor Fabiano Neves Macieywski (2010, p.183):

Sem cuidado com o meio ambiente, não haverá soberania, não haverá autodeterminação dos povos, não haverá respeito, não haverá mercado, consumidores, globalização, não haverá dignidade, não haverá vida, não haverá futuro.

A implementação do direito ao desenvolvimento constitui a base para o fortalecimento de outros direitos previstos na Declaração Universal dos Direitos Humanos, como o direito à saúde, à qualidade de vida, à liberdade, à moradia, bem como detém a pobreza e a discriminação. Desta forma, constata-se que o direito ao meio ambiente e o direito ao desenvolvimento consolidam-se como Direitos Humanos interdependentes e inseparáveis, conceitos muito bem interligados pela Convenção de Estocolmo. (KÄSSMAYER, 2010).

\section{DIREITOS HUMANOS, DIREITO FUNDAMENTAL E MEIO AMBIENTE}

O direito ao meio ambiente sadio e equilibrado compõe o mínimo existencial do ser humano e integra o sistema de Direitos Humanos. Consagrado no artigo 225 da Constituição da República brasileira, integra o rol dos Direitos Fundamentais.

Esta afirmação, hoje possível, deriva da evolução e afirmação dos Direitos Humanos ao longo da história, merecendo uma breve digressão para a sua devida compreensão.

$\mathrm{Na}$ história da Antiguidade, regras de cunho legal, moral, religioso, registradas em normativos, na filosofia e até na literatura, traziam em seu bojo a ideia de direitos do homem, defendendo-se a vida, a liberdade, a proteção da integridade física e do patrimônio, como no Código Hamurabi, Lei das XII Tábuas, no Evangelho. Contudo não se pode afirmar que havia uma sistematização de preceitos legais que assegurassem direitos dos indivíduos oponíveis ao próprio Estado, esta sistematização decorreu de uma evolução lenta e gradual. (MARUM, 2002). 
No final da Idade Média, transição para o Estado Moderno, o fenômeno da limitação do poder do Estado e o reconhecimento de direitos individuais ganhou força. Documentos históricos como Petition of Rights (1628), Habeas Corpus Act (1679), Bill of Rights (1689) e Act of Settlement (1701), sistematizaram preceitos, direitos individuais, afirmando a ideia de direitos imprescritíveis do homem.

A Declaração dos Direitos do Homem e do Cidadão de 1789, fruto da revolução francesa, é considerada o "atestado de óbito do Antigo Regime", na expressão de José Damião de Lima Trindade. (1998, p.94).

Neste contexto são defendidos direitos à liberdade, à propriedade, à segurança e o princípio da legalidade.

Com a ascensão de Napoleão ao poder em 1799, o constitucionalismo liberal-burguês expandiu-se pela Europa continental. E outra revolução, a industrial, que já havia se consolidado na Inglaterra no século XVIII, começa a ganhar corpo pela Europa, trazendo à tona os questionamentos ínsitos a concentração de riquezas nas mãos de uma minoria burguesa.

O século XIX é marcado por luta pela igualdade social pela grande massa de trabalhadores excluídos da riqueza e explorados pelo capitalismo nascente, contexto em que os direitos econômicos e sociais, relativos à saúde, habitação, educação, salário suficiente à sobrevivência, seguridade social, vão se afirmando no início do século XX, com as paradigmáticas Constituição Mexicana de 1917 e Constituição de Weimar, de 1919.

Aduz Jorge Alberto de Oliveira Marum (2002, p.1157) que até este ponto, os direitos eram formulados teoricamente e depois positivados na legislação interna de cada país.

Após a Segunda Guerra Mundial, surge o Direito Internacional dos Direitos Humanos, tendo como marco a Assembléia Geral das Nações Unidas, que culminou no texto da Declaração Universal dos Direitos Humanos de 1948, aprovado por unanimidade.

É importante destacar que a evolução dos Direitos Humanos não decorreu de um planejamento racional e linear, sendo o resultado de inúmeros conflitos. As graves violações de direitos, no contexto das atrocidades decorrentes das guerras mundiais, do nazismo, tornou necessário o reconhecimento e proteção dos Direitos Humanos por declarações, tratados e convenções assinados por diversos países, recebendo assim conotação internacional.

O princípio da dignidade humana é o vetor dos Direitos Humanos, e dele decorre a liberdade, igualdade e fraternidade. Assim como os Direitos Humanos, 
a questão ambiental, somente após a Segunda Guerra Mundial, obteve tônica internacional.

O Pacto Internacional de Direitos Econômicos, Sociais e Culturais de 1966 foi o primeiro diploma internacional que mencionou o meio ambiente. Não tratou a questão ambiental de maneira direta e per si, referindo-se a ele de forma reflexa, ao tratar do direito à saúde, compreendendo que medidas tendentes à melhoria do meio ambiente estariam dentre aquelas, capazes de assegurar o direito a um nível de vida adequado.

Segundo Cançado Trindade (1993, p.84), nesta menção, ainda que indireta, "parecia aberto o caminho para o reconhecimento futuro do direito a um meio ambiente sadio".

Importante destacar que a Declaração de Estocolmo instituiu princípios básicos do Direito ambiental. A partir dela, as Constituições dos Estados passaram a conferir aspectos protetivos ao ambiente, sendo, por isso, um marco internacional de proteção ambiental.

Neste sentido Valério de Oliveira Mazzuoli (2007, p. 178) aduz que:

Por ter materializado os ideais comuns da sociedade internacional no que toca à proteção internacional do meio ambiente, a Declaração de Estocolmo de 1972 abriu espaço para que esses temas, antes afetos ao domínio exclusivo e absoluto dos Estados, pudessem passar a ser tratados dentro de uma perspectiva global, notadamente ligada à proteção internacional dos direitos humanos.

Antes da Conferência de Estocolmo, o meio ambiente era tratado, em plano mundial, como algo dissociado da humanidade. A Declaração de Estocolmo de 1972 conseguiu, portanto, modificar o foco do pensamento ambiental do planeta, mesmo não se revestindo da qualidade de tratado internacional, enquadrando-se, ao lado das várias outras declarações memoráveis das Nações Unidas - de que são exemplos a Declaração Universal dos Direitos Humanos de 1948 (no campo dos direitos humanos) e a Declaração do Rio de Janeiro sobre Meio Ambiente e Desenvolvimento de 1992 (na esfera da proteção internacional do meio ambiente) - no âmbito daquilo que se convencionou chamar de soft law ou droit doux (direito flexível), governado por um conjunto de sanções distintas das previstas nas normas tradicionais, em contraponto ao conhecido sistema do hard law ou droit dur (direito rígido). Apesar de não se ter ainda, na doutrina internacionalista, uma conceituação adequada de soft law, pode-se afirmar que na sua moderna acepção ela compreende todas aquelas normas que visam regulamentar futuros comportamentos dos Estados, sem deterem o status de "norma 
jurídica", e que impõem além de sanções de conteúdo moral, também outras que podem ser consideradas como extrajurídicas, em caso de descumprimento ou inobservância de seus postulados.

Influenciada pela Declaração de Estocolmo, como já mencionado, a Constituição da República (BRASIL, 1988) positivou no artigo 225 o direito ao meio ambiente ecologicamente equilibrado como Direito Fundamental, indo além da perspectiva de Direitos Humanos.

Merece destacar que as expressões "Direitos Humanos" e "Direitos Fundamentais" não são sinônimos, considerando a dimensão internacional e nacional.

A expressão "Direitos Humanos" refere-se aos documentos internacionais em que Estados Soberanos reconhecem direitos aos seres humanos, decorrentes da matriz dignidade humana.

Já o termo "Direitos Fundamentais" alude a positivação no âmbito constitucional de um Estado. São os direitos reconhecidos e outorgados pelo direito constitucional interno de cada país.

Segundo Ingo Wolfgang Sarlet (2011, p.32), reconhecer a diferença entre as expressões Direitos Humanos e Direitos Fundamentais não é desconsiderar a íntima relação entre elas, "uma vez que a maior parte das Constituições do segundo pós-guerra se inspirou tanto na Declaração Universal de 1948, quanto nos diversos documentos internacionais e regionais que as sucederam”.

Segundo o texto constitucional brasileiro, o meio ambiente é um Direito Humano Fundamental, reconhecendo-o essencial à sadia qualidade de vida, ou seja, vincula-o ao mínimo existencial do ser humano.

Considerou o constituinte brasileiro que o meio ambiente ecologicamente equilibrado é um uma condição sine qua non do direito à vida.

\section{DESENVOLVIMENTO SUSTENTÁVEL E A EFETIVIDADE DAS NORMAS DE PROTEÇÃO AMBIENTAL}

Com o surgimento da era industrial, as práticas ofensivas ao meio ambiente se intensificaram devido a vários fatores como o avanço tecnológico, o crescimento da população, aumento da exploração dos recursos naturais, dentre outros.

Mesmo assim, esse processo foi suportado pelo meio ambiente devido a sua alta capacidade de regeneração ou resiliência. Contudo, quando se percebeu 
que este habitat poderia ser finito, saturado, iniciou-se um movimento de conscientização dos riscos do agir humano.

Portanto, os movimentos ecológicos somente se tornaram expressivos quando os efeitos de degradação ambiental começaram a repercutir na qualidade de vida da sociedade. Esta necessitou promover mecanismos de proteção ao meio ambiente, pois é ele que garante em parte a concretização dos Direitos Fundamentais à vida e à dignidade humana. (PIOVESAN, 2010).

De fato, somente no pós-guerra é que ocorreu uma evolução do pensamento acerca do desenvolvimento sustentável, mas ainda voltado notadamente para o âmbito econômico. Paralelamente, alguns movimentos políticos e sociais referentes à preocupação ambiental começavam a pressionar os poderes públicos a se posicionarem frente a este binômio proteção e progresso.

Nesse cenário, desponta o relatório Brundtland, um documento inovador que apresentou o conceito de desenvolvimento sustentável para o discurso público e que serviu de fundamento para vários outros documentos.

Assim, o desenvolvimento sustentável foi definido pela Comissão Mundial sobre Meio Ambiente e Desenvolvimento (Nosso Futuro Comum) como "aquele que atende às necessidades do presente sem comprometer a possibilidade de as gerações futuras atenderem a suas próprias necessidades".

Isso quer dizer que a comunidade ambiental, usuária dos recursos naturais, não deve limitar suas ações às gerações presentes, mas responsabilizar-se na proteção desses recursos para as gerações futuras. A ideia a ser transmitida é a da conservação do ambiente saudável como um direito fundamental às gerações vindouras. A respeito do desenvolvimento sustentável o relatório assim dispõe:

Um mundo onde a pobreza e a desigualdade são endêmicas estará sempre propenso à crises ecológicas, entre outras. [...] O desenvolvimento sustentável requer que as sociedades atendam às necessidades humanas tanto pelo aumento do potencial produtivo como pela garantia de oportunidades iguais para todos. Na sua essência, o desenvolvimento sustentável é um processo de mudança no qual a exploração dos recursos, o direcionamento dos investimentos, a orientação do desenvolvimento tecnológico e a mudança institucional estão em harmonia e reforçam o atual e futuro potencial para satisfazer as aspirações e necessidades humanas. 
Com o amadurecimento da preocupação ambiental, outros eventos foram realizados como a Conferência Mundial sobre Meio Ambiente e Desenvolvimento Sustentável (Rio 92), que originou o plano de ação global chamado Agenda 21.

A Agenda 21 apresentou um conjunto diversificado de diretrizes pertinentes às questões de desenvolvimento econômico-social, conservação e administração de recursos, bem como a implementação de planos, programas e projetos que visam ao desenvolvimento sustentável e a qualidade ambiental. Transformou-se, portanto, na cartilha básica do desenvolvimento sustentável. Ela estimulou a cooperação internacional dando ênfase na gestão ambiental associada e participativa, subsidiando as legislações locais, estaduais e nacionais. (MILARÉ, 2011).

Não obstante o seu caráter documental internacional, a Agenda 21 dependerá, para sua efetivação, de sua incorporação nas agendas locais. Para tanto, foi elaborada a Agenda 21 Brasileira. Esta se mostrou como uma proposta real e exequível de desenvolvimento sustentável, respeitadas as limitações econômicas, político-institucionais e culturais do país. Ela não se traduz como um plano de governo, mas como um compromisso da sociedade para os eventos futuros. (MILARÉ, 2011).

Contudo, o avanço mais significativo se expressa na organização mundial em favor da proteção ambiental. Não é mais admissível aos Estados, a ideia do desenvolvimento a qualquer custo, uma vez que os danos ambientais são irreversíveis e irrecuperáveis.

Ademais, nota-se também a relevância de se considerar o indivíduo como parte dessa cadeia ambiental, inserido nela, e não mais apenas como um espectador que se apropria dos recursos naturais. O enfoque de uma concepção antropocêntrica protecionista, ou seja, aquela que visa à proteção ao meio ambiente, mas em função do interesse humano, não tem mais lugar, uma vez que o meio ambiente se torna um patrimônio de todos.

\section{O ORDENAMENTO JURÍDICO AMBIENTAL SOB A PERSPECTIVA HABERMASIANA}

O desafio atual para a legislação ambiental é a efetividade. A mera previsão normativa sem real implementação prática ou de pouca repercussão quanto aos objetivos colimados, além de não atender ao anseio social de proteção ambiental, esvaziam a legislação, reduzindo-a a função meramente simbólica. 
Sem efetividade e concretude das normas de proteção ambiental, todo o discurso internacional e nacional, desenvolvidos com maior ênfase e entusiasmo desde a Convenção de Estocolmo, pode, de fato, restar limitado à categoria de discurso.

A participação da sociedade como sujeito de direitos no processo de construção da norma, por meio da abertura do diálogo e viabilização de relações intersubjetivas entre os construtores da norma, com vistas à obtenção de um consenso, torna-se um fator de legitimação e de compreensão da norma, uma vez que esta passa a ser concebida pelos destinatários como resultado do consenso.

Neste contexto, é possível estabelecer correlação entre a filosofia habermasiana pertinente ao discurso democrático e à razão comunicativa, e a efetividade das normas ambientais.

Habermas, filósofo contemporâneo, aborda as questões referentes à razão a partir de uma razão comunicativa, contrapondo-se à concepção da razão oriunda da relação sujeito-objeto ou oriunda de um sujeito isolado de seu contexto histórico, social e cultural.

Segundo o filósofo, “[...] o paradigma do conhecimento de objetos tem de ser substituido pelo paradigma da compreensão mútua entre sujeitos capazes de falar e agir”. (HABERMAS, 1990, p.276).

Propõe, assim, uma filosofia discursiva baseada na comunicação entre os sujeitos por intermédio de uma linguagem que viabilize o consenso. O consenso é o objetivo a ser alcançado por meio da ação comunicativa, a qual viabiliza o espaço de diálogo entre os sujeitos como fator de compreensão, harmonização de interesses e legitimação das decisões, coordenadas a partir do discurso comunicativo.

Assim, o uso da linguagem entre os participantes em um agir comunicativo torna a conclusão democrática, uma vez que um consenso (ou um acordo) não pode ser imposto a partir de fora e nem forçado por uma das partes (HABERMAS, 1990, p. 71). Segundo Habermas:

Essa racionalidade comunicativa exprime-se na força unificadora da fala orientada ao entendimento mútuo, discurso que assegura aos falantes envolvidos um mundo da vida intersubjetivamente partilhado e, ao mesmo tempo, o horizonte no interior do qual todos podem se referir a um único e mesmo mundo objetivo. (HABERMAS, 2004, p.107). 
A linguagem como característica do ser homem possibilita o entendimento mútuo e a validade do discurso. A linguagem mediatiza toda relação significativa entre os sujeitos e o mundo da vida. A teoria dos atos de fala, através da qual buscará o sentido e a validade da comunicação estabelecida entre os sujeitos:

Os atos elementares de fala apresentam uma estrutura na qual se combinam três elementos: a componente proposicional para a representação (ou menção) de estados de coisas, a componente elocutória para a admissão de relações interpessoais e, finalmente, as componentes lingüísticas que experimentam a intenção de quem fala. (HABERMAS, 1990, p.289).

A comunicação livre, racional e crítica, com a participação dos sujeitos que dialogam intersubjetivamente em relação ao conteúdo das normas ambientais, implica a consciência de tais normas através da sensação de pertencimento.

O pertencimento é corolário do consenso advindo do diálogo democrático cujas consequências são a ciência sobre as normas ambientais robustecida pela consciência acerca da importância do cumprimento dessas mesmas normas.

A (cons)ciência do cidadão como sujeito de direitos ambientais implica maior efetividade dessas normas, porquanto viabilizará o exercício de tais direitos, ou seja, a apresentação de demandas e pleitos objetivando o cumprimento das normas ambientais pelo exercício, de fato, do Direito Fundamental ao meio ambiente ecologicamente equilibrado.

Na mesma medida, a (cons)ciência do cidadão como sujeito de deveres ambientais também amplia a efetividade de tais normas, tendo em vista que o pertencimento ao mundo de vida e ao contexto histórico-cultural dos sujeitos, após a discussão democrática, com uma linguagem que franqueia - ou viabiliza - o entendimento referente às normas ambientais construídas, torna o cumprimento das normas ambientais o reflexo de uma internalização não impositiva do conteúdo da norma.

A discussão das normas e política ambientais pela via da ação comunicativa proposta por Habermas viabiliza tanto a legitimidade das normas e sua efetividade pelo cidadão, como a construção do consenso inarredável à construção das normas e política ambientais no âmbito internacional, tendo em vista a abertura do espaço para a apresentação de críticas e a observância de uma linguagem que viabiliza o entendimento sobre o conteúdo das proposições. 
A ConcretizaÇão do ordenamento jurídico ambiental sob a luZ do pensamento habermasiano

\section{CONSIDERAÇÕES FINAIS}

Na estrutura nacional contemporânea, a Constituição da República de 1988 passou a adotar o discurso ambiental de forma bastante significativa, exatamente por dispor em seu texto a questão do ambiente como um bem fundamental a ser responsavelmente protegido. Nesse sentido, a legislação nacional internalizou as diretivas internacionais de proteção ambiental e, no presente estudo, destacou-se essa importância.

Percebeu-se, portanto, que o direito a um meio ambiente equilibrado está intimamente relacionado ao Direito Fundamental à vida e à proteção da dignidade da vida humana. O mínimo existencial ecológico apregoa condições míninas de preservação dos recursos naturais para a sobrevivência das futuras gerações. Resta afirmar que a dignidade da pessoa humana está diretamente vinculada à qualidade do meio ambiente.

O reconhecimento do direito ao meio ambiente como um Direito Humano Fundamental é assaz importante, e não implica mera formalidade. Ao integrar o rol de direitos fundamentais torna-se cláusula pétrea do regime constitucional pátrio, sendo um direito irrevogável e que não admite retrocesso.

Analisando pela proposta de Habermas, a racionalidade comunicativa propicia ao ser humano a oportunidade de refletir seus atos na sociedade mundial. A razão instrumental implicou um uso indiscriminado dos recursos naturais e uma instrumentalização do próprio ser humano, o que permeou a cultura do homem ocidental nos últimos séculos.

A utilização da filosofia habermasiana na discussão ambiental pode ser enriquecedora por viabilizar a democratização do discurso ambiental em proposições dotadas de maior legitimidade e, por conseguinte, de efetividade.

A relação dialética dotada de intersubjetividade entre os participantes de uma discussão ambiental torna o cumprimento dos deveres ambientais uma tarefa intrínseca ao próprio exercício dos direitos ambientais, de modo a imprimir a efetividade pela conscientização e participação na construção das proposições pela via da ação comunicativa.

\section{REFERÊNCIAS}

\section{BRASIL. Constituição da República Federativa do Brasil 1988.}

Brasília, Senado Federal. 1988. Brasília (DF), 2013. Disponível em $<$ http:// www.senado.gov.br/legislacao/const/con1988/CON1988_02.04.2013/ CON1988.shtm> Acessado em: 12 nov. 13. 
BENJAMIM, Antônio Herman de Vasconcellos. Introdução ao direito ambiental brasileiro. Revista de Direito Ambiental. RDA 14/48. Abr-jun/1999.

CANÇADO TRINDADE, Antonio Augusto. Direitos humanos e meio ambiente: paralelo dos sistemas de proteção internacional. Porto Alegre: Fabris, 1993.

CRUZ, Álvaro Ricardo de Souza. O direito à diferença. Belo Horizonte: Arraes editores, 2009.

COSTA, Beatriz Souza. Meio Ambiente como direito à vida: Brasil, Portugal, Espanha. Belo Horizonte: O Lutador, 2010.

FIORILlO, Celso Antônio Pacheco. Curso de direito ambiental brasileiro. 14. ed. São Paulo: Saraiva, 2013.

FONSECA, Daniela Rodrigueiro Peres. A dignidade da pessoa humana: razão de existência das tutelas ambientais. Revista do Instituto de Pesquisas e Estudos, Bauru, n. 29, p.287-294, ago./nov. 2000.

HABERMAS, Jürgen. O discurso filosófico da modernidade. Trad. Ana Maria Bernardo et al. Lisboa: Dom Quixote, 1990.

. Verdade e Justificação: ensaios filosóficos. Trad. Milton Camargo Mota. São Paulo: Loyola, 2004.

KÄSSMAYER, Karin. Desenvolvimento sustentável como princípio fundamental dos direitos humanos. In: PIOVESAN, Flávia (Coord.). Direitos Humanos, volume I. Curitiba: Juruá Editora, 2010. P.221-242.

MACHADO, Paulo Affonso Leme. Direito ambiental brasileiro. 21.ed. rev., atual e ampl. São Paulo: Malheiros, 2013.

MACIEYWSKI, Fabiano Neves. Universalidade humana e ambiental. In: PIOVESAN, Flávia (Coord.). Direitos Humanos, volume I. Curitiba: Juruá Editora, 2010. P.182-190. 
MARQUES, José Roque Nunes. A Constituição Federal e o meio ambiente. Cidadania e Justiça, Rio de Janeiro, v. 4, n. 9, p.26-31, 2000.

MARUM, Jorge Alberto de Oliveira. Meio ambiente e direitos humanos. Revista de Direito Ambiental. RDA 28/117. out-dez./2002.

MAZZUOLI, Valério de Oliveira. Revista Amazônia legal de estudos sócio-jurídico-ambientais. Cuiabá, Ano 1, n. 1, p. 169-196, jan.-jun. 2007.

MILARÉ, Édis. Direito do ambiente: a gestão ambiental em foco. Doutrina, jurisprudência e glossário. 7. ed. São Paulo: Revista dos Tribunais, 2011.

MORATO, Antonio Carlos. A proteção jurídica do bem ambiental. FMU Direito, São Paulo, v. 16, n. 24, p.61-83, 2002.

MOREIRA, J. C. Tutela jurisdicional dos interesses coletivos ou difusos. Temas de Direito Processual, Terceira Série, 1984.

ONU - Organização das Nações Unidas. Declaração do Rio sobre o meio ambiente e desenvolvimento. Rio de Janeiro: 2012. Disponível em: $<$ http://www.onu.org.br/rio20/img/2012/01/rio92.pdf $>$ Acessado em 12 Nov. 2013.

PIOVESAN, Flávia. Direitos humanos: desafios da ordem internacional contemporânea. In: PIOVESAN, Flávia (Coord.). Direitos Humanos, volume I. Curitiba: Juruá Editora, 2010. P.15-37.

PIOVESAN, Flávia. Direitos humanos e o direito constitucional internacional. 11 a ed. São Paulo: Saraiva, 2010.

SARLET, Ingo Wolfgang. A eficácia dos direitos fundamentais. Porto Alegre: Livraria do Advogado, 2011.

SILVA, José Afonso da. Fundamentos constitucionais da proteção do meio ambiente. Revista de Direito Ambiental, São Paulo, v. 7, n. 27, p.51-57, jul./set. 2002. 
SMANIO, Gianpaolo Poggio. A tutela constitucional do meio ambiente. Revista de Direito Ambiental, São Paulo, v. 6, n. 21, p.286-290, jan./mar. 2001.

TRINDADE, José Damião de Lima. Anotações sobre a história social dos direitos humanos in Direitos Humanos: construção da liberdade e da igualdade. São Paulo: Centro de Estudos da Procuradoria Geral do Estado, 1998.

THOMÉ, Romeu. Manual de direito ambiental. 2. ed. Salvador: JusPodivm, 2012.

VEIGA, José Eli. Desenvolvimento sustentável: o desafio do século XXI. Rio de Janeiro: Garamond, 2010.

Artigo recebido em: 23/03/2014 Aprovado para publicação em: 02/08/2014

Como citar: REIS, Émilien Vilas Boas. COSTA, Marina Lage Pessoa. A concretização do ordenamento jurídico ambiental sob a luz do pensamento habermasiano. Revista do Direito Público. Londrina, v.9, n.2, p.9-24, mai./ago.2014. DOI: 10.5433/1980-511X.2014 v9n2p9. 